\title{
CAMPO DE ESFORÇOS PLIO-PLEISTOCÊNICO NA ILHA DA TRINDADE (OCEANO ATLÂNTICO SUL, BRASIL) E SUA RELAÇÃO COM ATECTÔNICA REGIONAL
}

\author{
ANDRÉ LUIZ FERRARI* E CLÁUDIO RICCOMINI**
}

\begin{abstract}
PLIO-PLEISTOCENIC STRESS FIELD IN THE TRINDADE ISLAND (SOUTHERN ATLANTIC OCEAN, BRAZIL) AND ITS RELATIOSHIP WITH THE REGIONAL TECTONICS The volcanic island of Trindade, of alkaline nature, is the emerged portion of a large volcanic building whose base is submerged about $5000 \mathrm{~m}$ depth. The analysis of the pattern of orientation of the Pliocene-Pleistocene dike swarm of the northeast portion of the island, as well as of the lengthening of phonolithic plugs, has allowed the determination of an NW direction of $\mathrm{SH}_{\max }$ (in the case corresponding to $\sigma 1$ ) during the emplacement of the intrusive bodies, compatible with an ENE-WSW to E-W right-lateral binary. The direction determined for $\sigma \mathrm{l}$ in the island is parallel to the larger axis of the volcanic building, suggesting the same tectonic control during its formation. On the other hand, the Vitória-Trindade Chain shows differentiated segments with NW-SE, NE-SW and E-W directions, probably corresponding to changes in the direction of $\sigma 1$ during the Tertiary in this oceanic portion of the South American Plate. These changes are partly compatible with the variations verified in the adjoining continental portion of Southeastern Brazil. Differences in the depth of the basement to the north and to the south of the Vitória-Trindade Chain corroborate its behavior as a fracture zone, that would have acted as conduit for the magmatism associated with the Trindade Plume. The incompatibility verified between the expected direction of $\mathrm{SH}_{\max }$ during the Pliocene and Pleistocene in the Trindade Island and the direction of the studied dikes implies in a non-rigid behavior of this segment of the South American Plate.

Keywords: Trindade Island, stress-field, Pliocene, Pleistocene, South Atlantic, fracture zone.
\end{abstract}

RESUMO A Ilha da Trindade, de natureza vulcânica alcalina, é a porção emersa de um grande edifício vulcânico cuja base encontra-se submersa a cerca de $5000 \mathrm{~m}$ de profundidade. A análise do padrão de orientacão do enxame de diques plio-pleistocênicos da porção nordeste da ilha, como também do alongamento de plugs fonolíticos, permitiu a determinação da direção de $\mathrm{SH}_{\max }$ (no caso correspondente a $\sigma 1$ ) segundo N60W, durante a colocação desses corpos intrusivos. O regime tectônico seria do tipo transcorrente dextral, com binário de orientação geral ENE-WSW a E-W. A direção determinada para $\sigma 1$ na Ilha da Trindade é paralela ao eixo maior do edifício vulcânico, sugerindo a vigência do mesmo controle tectônico durante sua formação. Por outro lado, a Cadeira Vitória-Trindade mostra segmentos diferenciados com direções NW-SE, NE-SW e E-W, provavelmente correspondentes a mudanças na direção de ol durante o Terciário nesta porção oceânica da Placa Sul-Americana, em parte compatíveis com as variações verificadas na porção continental emersa adjacente no sudeste do Brasil. Diferenças na profundidade do embasamento ao norte e ao sul da Cadeia Vitória-Trindade corroboram o comportamento desta como uma zona de fratura, que teria atuado como conduto para o magmatismo da Pluma da Trindade. A incompatibilidade verificada entre a direção de $\mathrm{SH}_{\max }$ esperada para o Plioceno e Pleistoceno na Ilha da Trindade e a direção dos diques estudados implica num comportamento não rígido deste segmento da Placa Sul-Americana.

Palavras-chave: Ilha da Trindade, campo de esforços, Plioceno, Pleistoceno, Oceano Atlântico Sul, zona de fratura.

INTRODUÇÃO Um dos preceitos básicos da Teoria da Tectônica de Placas é o de que as placas tectônicas são rígidas e a deformacão se restringe aos limites convergente e divergente (Wilson 1965, Morgan 1968). Segundo Wilson (1965) os limites transformantes teriam movimentação puramente direcional, conservativo, e fora dos segmentos entre as cristas da cordilheira meso-oceânica as falhas transformantes deixariam de se movimentar, constituindo, a partir daí, os segmentos inativos das zonas de fraturas. Entretanto, em estudos recentes vêm sendo registradas evidências de comportamento não rígido das placas, tais como velocidade de movimentação não homogénea longitudinal e transversalmente à cordilheira meso-oceânica, no intervalo de tempo de uma anomalia magnética (Carbotte et al. 1991, Fox et al. 1991), e presença de deformação e magmatismo intraplaca, em crosta oceânica, como na Cordilheira $90^{\circ} \mathrm{E}$, no Oceano Índico (Wiens et al. 1986), na Cordilheira de Puca-Puca (Sandwell et al. 1995), na Zona de Fratura Orongo (Binard et al. 1996) e na Zona de Fratura Marquesas, no Pacífico Sul (McNutt et al. 1989, Jordhal et al. 1995), nas Ilhas Canárias, no Atlântico Norte (Marinoni \& Pasquarè 1994, Fernandez et al. 1997) e, também, no Atlântico Sul, na Zona de Fratura de Fernando de Noronha (Gomes 1997), ou em cadeias assísmicas de direção NW (Fleitout et a/.1989), como os montes submarinos da Bahia e de Pernambuco (Gorini\& Carvalho 1984, Mello \& Dias 1996). Os processos envolvidos nestas reativações intraplaca estão relacionados predominantemente a uma conjugação de esforços regionais, em geral aluando sobre zonas de fraturas, com plumas mantélicas (Lowrie et al. 1986, Jordahl et al. 1995, Kruse et al. 1996).

O propósito deste artigo é o de, a partir de uma releitura do trabalho clássico de Almeida (1961), utilizando dados de orientação de diques e fraturas, discutir o papel dos esforços regionais no controle tectônico do magmatismo na Ilha da Trindade e na formação da própria Cadeia Vitória-Trindade, ambas aparentemente associadas à reativação da Zona de Fratura Vitória-Trindade em conjugacão com a Pluma de Trindade (Szatmari \& Mohriak 1995, Conceição et al. 1996). Para tanto, foram consideradas as variações na direção de movimentação da Placa Sul-Americana, tendo em vista a sua influência na distribuição dos tensores regionais (Zoback et al. 1989, Richardson 1992, Stefanick \& Jurdy 1992, Coblentz \& Richardson 1996) e, ainda, as variações na velocidade de movimentação desta placa.

*Departamento de Geologia/Lagemar, Universidade Federal Fluminense e Bolsista PICDT/CAPES, Programa de Pós-Graduação em Geologia Sedimentar, Instituto de Geociências, Universidade de São Paulo. Caixa Postal 11.348, CEP 05422-970, São Paulo, SP, Brasil. Fax: 5511 8184129,E-mail: andref@usp.br **Instituto de Geociências, Universidade de São Paulo e Bolsista de Pesquisa do Conselho Nacional de Desenvolvimento Científico e Tecnológico - CNPq. Caixa Postal 11.348, CEP 05422-970, São Paulo, SP, Brasil. Fax: 5511 8184129. E-mail: riccomin@usp.br
A porção continental da Placa Sul-Americana mostra uma distribuicão relativamente regular de $\mathrm{SH}_{\max }$ segundo a direção geral WNW-ESE a E-W (Zoback et al. 1989, Zoback 1992), aproximadamente paralela ao sentido atual de deslocamento da placa; as discrepâncias são interpretadas como decorrentes de esforços locais, entendidos principalmente como forças topográficas locais associadas a áreas elevadas e forças de espalhamento associadas ao contraste local de densidade entre diferentes segmentos crustais, como no caso das margens continentais (Zoback 1992, Coblentz \& Richardson 1996, Zoback \& Richardson 1996, Assumpção 1998). Entretanto, são raras as indicações de direções de esforços para a porção oceânica desta plaça, não permitindo qualquer tipo de correlação com estruturas regionais.

Dessa maneira, os parâmetros obtidos para a Cadeia Vitória-Trindade são comparados com as variações na distribuição dos esforços na área emersa adjacente, durante o Terciário e o Quaternário.

Para a determinação dos campos de esforços atuantes na Ilha da Trindade durante sua formação considerou-se essencialmente as orientações de diques e as orientações dos eixos maiores e menores de plugs fonolíticos com forma elíptica. Diques são bons indicadores tectônicos uma vez que se posicionam a $90^{\circ}$ do tensor de menor esforço $\sigma 3$ (Anderson 1951). Geoffroy et al. (1993) encontraram boa concordância entre $\sigma 1$ e $\sigma 2$ calculados tanto através da orientação de diques, como a partir do movimento das falhas, para um mesmo campo de esforços. Esta relação é válida também para focos vulcânicos e para corpos intrusivos e, ainda, não apenas para estruturas puramente tracionais, mas também para as transtracionais (Tchalenko 1970, Wilcox et al 1973, Geoffroy et al. 1993, Basset \& Kleinspein 1996).

GEOLOGIA DA ILHA DA TRINDADE A ilha vulcânica da Trindade $\left(20^{\circ} 30^{\prime} \mathrm{S}\right.$ e $\left.29^{\circ} 19^{\prime} \mathrm{W}\right)$, de natureza essencialmente alcalina, é a porção aflorante, com menos de $600 \mathrm{~m}$ de altitude, de um edificio vulcânico cuja base encontra-se submersa a cerca de $5000 \mathrm{~m}$ de profundidade. Com cerca de $8 \mathrm{~km}^{2}$ de área emersa, este edifício vulcânico possui uma base aproximadamente elíptica, com eixo maior de $67 \mathrm{~km}$ e menor de $28 \mathrm{~km}$ (Figura 1). A Ilha da Trindade apresenta quatro centros vulcânicos, estabelecidos sobre o "Complexo de Trin-
dade", constituído por tufos fonolíticos; por domos, necks e diques 
fonolíticos e, subordinadamente, por tufos e diques lamprofíricos (Almeida 1961) (Figura 2). Dos quatro centros vulcânicos, de composição lamprofírica, nefelínítica e fonolítica, os do Valado e do Paredão são os mais novos e tiveram uma idade holocênica inferida por critérios geomorfológicos (Almeida 1961). Mais de uma centena de diques foram mapeados por Almeida (1961); eles possuem espessura decimétrica a decamétrica, com mergulho vertical amplamente predominante.

As idades K-Ar disponíveis (Cordani 1970, Cordani \& Blazekovic 1970, Valencio \& Mendía 1974), recalculadas segundo as novas constantes de decaimento (Dalrymple 1974), indicam que a atividade magmática na ilha teve início a partir do Plioceno ( $3.4 \mathrm{Ma})$, com maior intensidade entre 2.4 e $2.9 \mathrm{Ma}$, estendendo-se até o Holoceno (Figura 3). Estes valores estão em flagrante contraste em relação à idade da crosta oceânica sobre a qual a ilha está situada, estimada em cerca de $79 \mathrm{Ma}$, já que ela se encontra entre as anomalias magnéticas 34 (84 Ma) e 33 (74,3 Ma) (Cande et al. 1988).

ESTRUTURAS DA ILHA DA TRINDADE Os numerosos diques que ocorrem na Ilha da Trindade, em sua maior parte fonolíticos, constituem dois enxames com direções distintas. No primeiro deles,

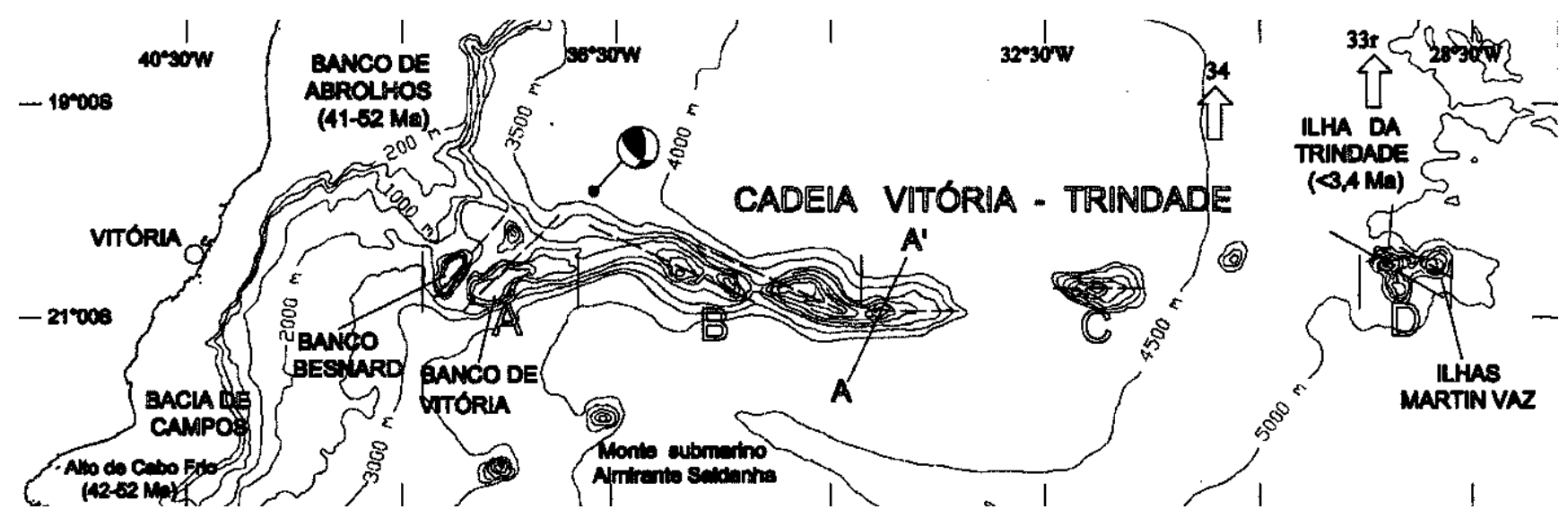

Figura 1 - Mapa batimétrico da Cadeia Vitória-Trindade mostrando os segmentos tectônicos inferidos A, B, C e D (linhas tracejadas) com orientação distinta. Dados batimétricos a partir do Atlas Digital GEBCO (IOC-IHD) do ano de 1997. Posição das anomalias magnéticas 34 (84,00 Ma) e $33 \mathrm{r}$ (80,17 Ma) a partir de Schobbenhaus et al. (1984) e Cande et al. (1988). As setas convergentes indicam a direção de SH ${ }_{\text {max }}$ (N60W), durante o Plio-Pleistoceno, na Ilha da Trindade. O mecanismo focal reverso diz respeito ao sismo de 1955, de intensidade 6,2 (mb) (Mendiguren \& Richter, 1978). Idade do vulcanismo no Banco de Abrolhos a partir de Cordani (1970) e Cordani \& Blazekovic (1970). Idade do vulcanismo no Alto de Cabo Frio a partir de Mohriak et al (1990). A-A'se refere à localização do perfil sísmico interpretado na Figura 6.

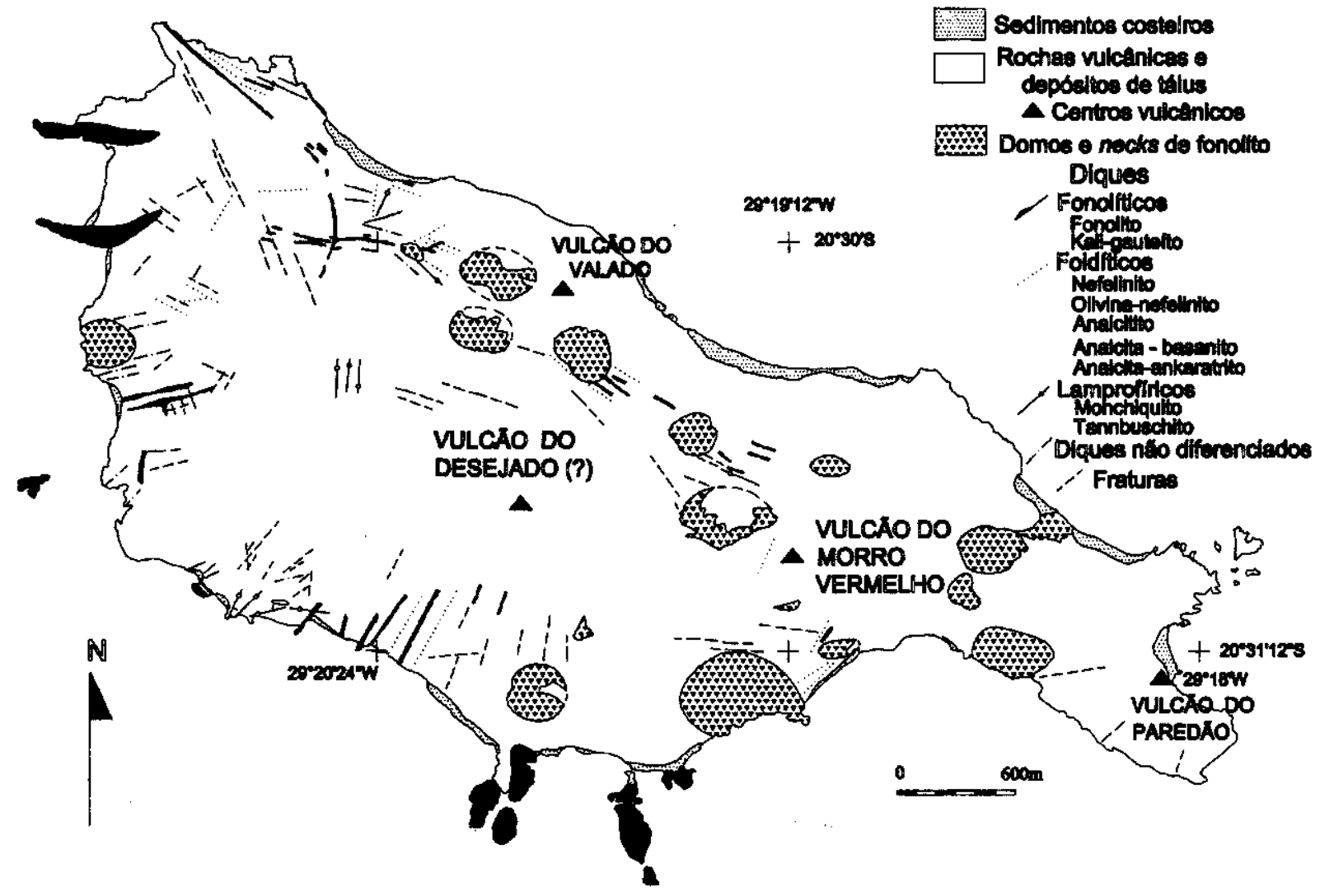

Figura 2 - Mapa geológico simplificado da Ilha da Trindade. Modificado de Almeida (1961). 


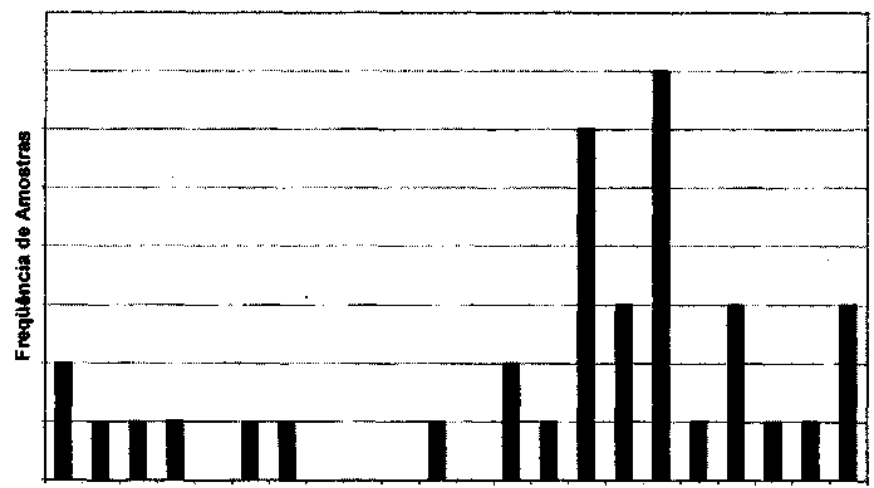

$0=7.0-1.1-1.2-1.3-1.4-1.5-1.6-1.7-1.5-1.9-2.0-2.1-22-2.3-2.4-2.5-25-27-2.8-2.9-3.0-$

Idades (Ma)

Figura 3 - Idades K-Ar das rochas da Ilha da Trindade, recalculadas segundo as novas constantes de decaimento (Dalrymple 1974), a partir de Cordani (1970) e Valendo \& Mendía (1974).

situado no compartimento nordeste da ilha, a plotagem em diagrama de rosácea da direção de 70 diques e 26 fraturas, medidos em mapa, evidenciou uma concentração segundo a direção N58W (Figuras 2 e 4a). No segundo, situado no compartimento sudoeste da ilha, a plotagem em diagrama de rosácea da direção de 34 diques e 33 fraturas, medidos em mapa, mostrou uma distribuição radial, apesar de uma maior populacão no quadrante nordeste (Figuras $2 \mathrm{e} 4 \mathrm{~b}$ ). Esta distribuição radial está possivelmente relacionada ao centro vulcânico do Desejado, ali presente. Plugs fonolíticos predominam no compartimento nordeste e apresentam forma elíptica, com eixo maior também orientado segundo a direção NW (Figuras 2 e 4c). A plotagem em diagrama de rosácea da direção do eixo maior de oito plugs, medidos em mapa, mostrou uma concentração segundo a direção N61W, compatível com a dos diques do mesmo compartimento. Apesar do pequeno número de determinações geocronologicas disponíveis para os diques do compartimento sudoeste, estas não evidenciam um diacronismo em relacão aos do compartimento nordeste (Cordani 1970, Cordani \& Blazekovic 1970, Valendo \& Mendía 1974).

A orientação dos diques e plugs e o padrão de fraturamentos do domínio nordeste permitem situar o eixo de tensões principal mínimo, $\sigma 3$, na direção NE, ortogonal a direção dos diques, enquanto que a direção N60W corresponderia a orientação de $\mathrm{SH}_{\max }$. Essa direção de esforcos contemplaria regimes alternativos, do tipo extensional $(\sigma 1$ vertical) ou de cisalhamento simples ( $\sigma 1$ horizontal, na direção dos diques). Considerando-se o mergulho vertical predominante do conjunto de diques e fraturas (Figura 5), o regime tectônico exige $\sigma 2$ vertical, o que, no presente caso, favorece o modelo de cisalhamento simples, com $\sigma 1$ horizontal na direção NW-SE, associado a um binário dextral de orientação aproximada segundo ENE-WSW a E-W, em resposta aos esforços regionais ou a uma conjugação destes com os esforços locais. Em alguns segmentos da Cadeia Vitória-Trindade, inclusive naquele constituído pelas ilhas da Trindade e Martin Vaz, os eixos maiores dos edifícios vulcânicos apresentam, numa escala regional, um arranjo en echelon, reforçando as inferências de movimentações direcionais, associadas a esforços regionais (Figura 1).

A Cadeia de Vitória-Trindade, embora com orientação geral E-W, mostra segmentos com direções NW-SE e NE-SW, além de E-W (Figura 1). No caso da Ilha da Trindade, a direção NW-SE de $\mathrm{SH}_{\max }$ é paralela ao eixo maior do edifício vulcânico. Se as direções de $\mathrm{SH}_{\max }$ nos demais segmentos da cadeia seguirem também o alinhamento dos edifícios vulcânicos, estarão, neste caso, refletindo mudanças na distribuição dos tensores durante sua formação.

CADEIA VITÓRIA-TRINDADE A Ilha da Trindade situa-se no limite oriental da Cadeia Vitória-Trindade, a qual constitui-se em uma feição geomorfológica descrita pelo alinhamento de bancos e montes submarinos, na direção geral E-W, entre os paralelos $20^{\circ}$ e $21^{\circ} \mathrm{S}$. Esta cadeia estende-se por cerca de $1000 \mathrm{~km}$, desde os bancos submarinos Besnard e de Vitória, a oeste, até as ilhas da Trindade e Martin Vaz, a leste (Figura 1). Estes bancos submarinos se caracterizam por serem elevações de topo aplainado, situados a profundidades inferiores a $100 \mathrm{~m}$, que se elevam de profundidades de até $5000 \mathrm{~m}$ desde o talude e o sopé continentais. A cadeia é mais larga em direção a oeste, em função
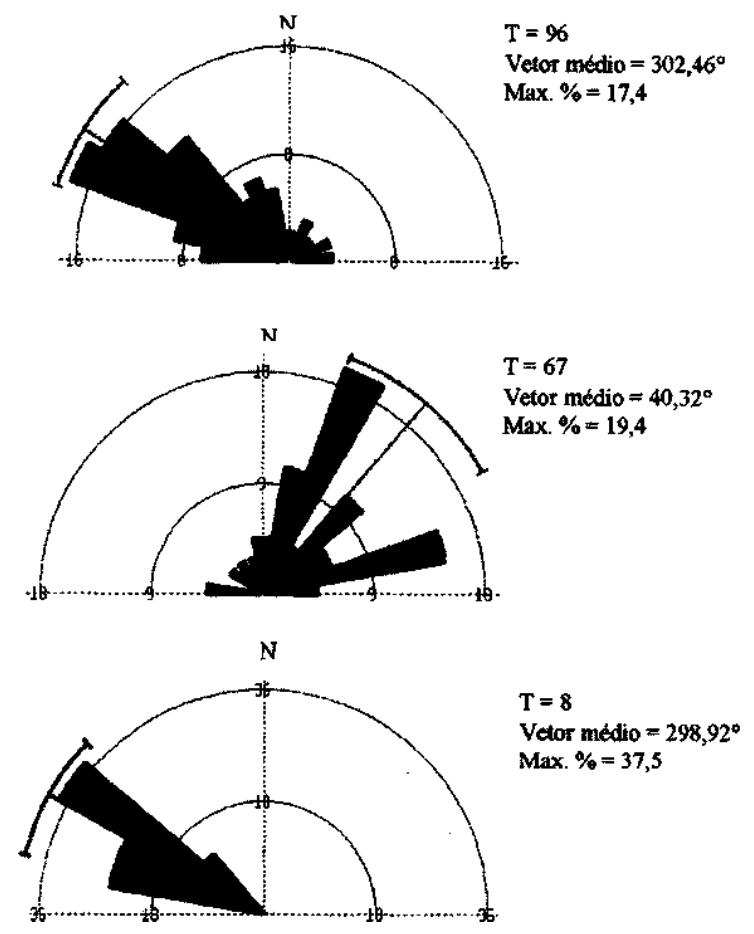

Figura 4 - Diagramas de rosáceas de diques e fraturas na porção nordeste $(A)$ e sudoeste da Ilha da Trindade. O diagrama $(C)$ refere-se às orientações dos eixos maiores de domos fonoliticos com forma elíptica. $O$ azimut está relacionado ao norte geográfico e as classes correspondem a intervalos de $10^{\circ}$. Os semi-circulos fornecem uma referência para a percentagem em cada classe. Té o número total de diques e fraturas ou de plugs, em cada área.

SW

NE

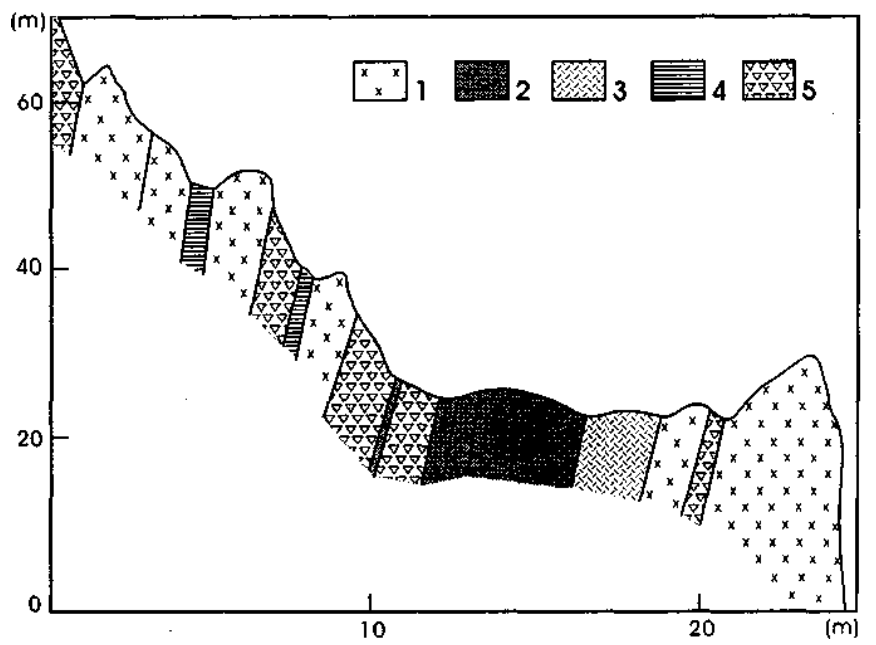

Figura 5 - Diques múltiplos expostos na costa norte da Ilha da Trindade, entre a Praia dos Cabritos e a Ponta do Galo. 1-fonolitos, 2 - nefelinitos, 3 - basanitos, 4 - lamprófiros, 5 - tufos fonolíticos do Complexo de Trindade. Modificado de Almeida (1961). 
da coalescência dos bancos e montes submarinos (Gorini \& Carvalho 1984) pelo desenvolvimento de recifes carbonáticos de algas e briozoários (Palma 1984). A Cadeia de Vitória-Trindade tem sido associados o Arquipélago dos Abrolhos (Cordani \& Blazekovic 1970) e o Banco de Abrolhos (Asmus et al. 1971), localizados na plataforma continental (Figura 1). A natureza vulcânica da Cadeia Vitória-Trindade foi originalmente proposta por Almeida $(1961,1965)$, a partir de estudos geológicos na Ilha da Trindade e seria confirmada pela dragagem de rochas vulcânicas na sua porção mediana (Guazelli \& Carvalho 1978). A presenca de crosta espessada sob a cadeia (Aguiar 1997) reforça essa assertiva. Para Guazelli \& Carvalho (1978) o alinhamento desta feição com picos e desnivelamentos do embasamento para leste, em direcão à cordilheira meso-oceânica, permitiriam sua caracterização como uma zona de fratura, por eles denominada de Zona de Fratura Vitória-Trindade, a qual, segundo Guazelli \& Carvalho (1981), pode ser mapeada até o meridiano $19^{\circ} \mathrm{W}$, a cerca de $1000 \mathrm{~km}$ a leste da Ilha de Martin Vaz. Esta caracterização confirmaria a inferência de Francheteau \& Le Pichon (1972) de que a Cadeia Vitória-Trindade coincidiria com a "direção transformante $40,4^{\circ}$, coincidente também, segundo eles, com o limite sul da Bacia de Cuanza, no lado africano. A limitada definição da crista da cordilheira meso-oceânica e de eventuais deslocamentos desta no prolongamento da proposta Zona de Fratura Vitória-Trindade (Cande et al. 1988) dificultam a confirmação desta hipótese. Porém, na margem continental, a Cadeia Vitória-Trindade coincide com o limite norte do Alto de Vitória e o limite sul da Bacia do Espírito Santo (Guazelli \& Carvalho 1981), caracterizada ali pela presença do Banco de Abrolhos, constituindo uma plataforma anomalamente larga, com $240 \mathrm{~km}$ de largura (Carvalho \& Francisconi, 1981), e por uma crosta bastante estendida, com $\beta=2,80$ (Chang et al. 1992), indicando a presenca de uma importante descontinuidade litosférica desde a implantação da margem continental. Na bacia oceânica a Cadeia Vitória-Trindade limita domínios com sedimentação de características e espessura distintas (Gorini \& Carvalho, 1984), com diferentes profundidades do embasamento (Figuras l e 6) e, ainda, com comportamento magnético distinto (Guazelli \& Carvalho 1981), sugerindo que esta descontinui- dade litosférica esteve presente também na crosta oceânica desde a sua formação, reforçando a hipótese da presença de uma zona de fratura.

No prolongamento da Cadeia Vitória-Trindade para a área continental emersa tem-se a ocorrência de rochas alcalinas, kimberlitos e carbonatitos, na região do Alto do Paranaíba, com idade média de 85 Ma (Gibson et al. 1995), que tem sido utilizada em conjunto com o vulcanismo basáltico do Banco de Abrolhos, com idades entre 52 e 41 Ma (Cordani 1970, Cordani \& Blazekovic 1970) e o vulcanismo alcalino das ilhas da Trindade e Martin Vaz, para a proposição de um modelo do tipo hotspot (Herz 1977, Crough et al. 1980, Morgan 1983, O'Connor \& Duncan 1990, Gibson et al. 1995). Para estes autores os diversos eventos vulcânicos poderiam ser explicados pelo movimento da Placa Sul-Americana sobre a Pluma de Trindade, nos últimos 90 Ma.

A maior parte das reconstituições da movimentação da Placa SulAmericana para o Cenozóico são compatíveis com arranjo E-W da Cadeia Vitória-Trindade, apesar de divergirem com relação à movimentação cretácea, entre uma migração para oeste (Herz 1977, Hartnady \& Le Roex 1985), ou para noroeste (Crough et al. 1980, Morgan 1983,0'Connor \& Duncan 1990). Para Fleitout et al. (1989) a migração para oeste da Placa Sul-Americana teria se iniciado há $30 \mathrm{Ma}$, já na metade do Terciário, tendo sido precedida por deslocamentos para $\mathrm{WNW}\left(\mathrm{N} 63^{\circ} \mathrm{W}\right)$ entre 30 e $80 \mathrm{Ma}$.

O'Connor \& Duncan (1990) consideram que os bancos Sulfur, Minerva, Lothrop, Morgan, Rodger e Hotspur, localizados ao norte do Banco de Abrolhos, e o Banco Almirante Saldanha, localizado ao sul, deveriam ser incluídos na Cadeia Vitória-Trindade, ampliando a área de atuação da Pluma de Trindade para aproximadamente $600 \mathrm{~km}$ na direção NS. Esta inferência é compartilhada por Gibson et al. (1995), que explicam a diminuicão da faixa de atuação da Pluma de Trindade para aproximadamente $100 \mathrm{~km}$ de largura nas porções mais distais, a uma atuação associada à cauda da pluma (plume tail). Segundo Gibson et al. (1995) a Pluma de Trindade teria ficado inativa no Terciário Inferior, com relação à geração de vulcanismo, por ocasião da passagem do Craton do São Francisco sobre ela, com seus $200 \mathrm{~km}$ de espessura litosférica (Van Deccar et al. 1995), e teria retomado sua

LEPLAC VII - Perfil 500-0514

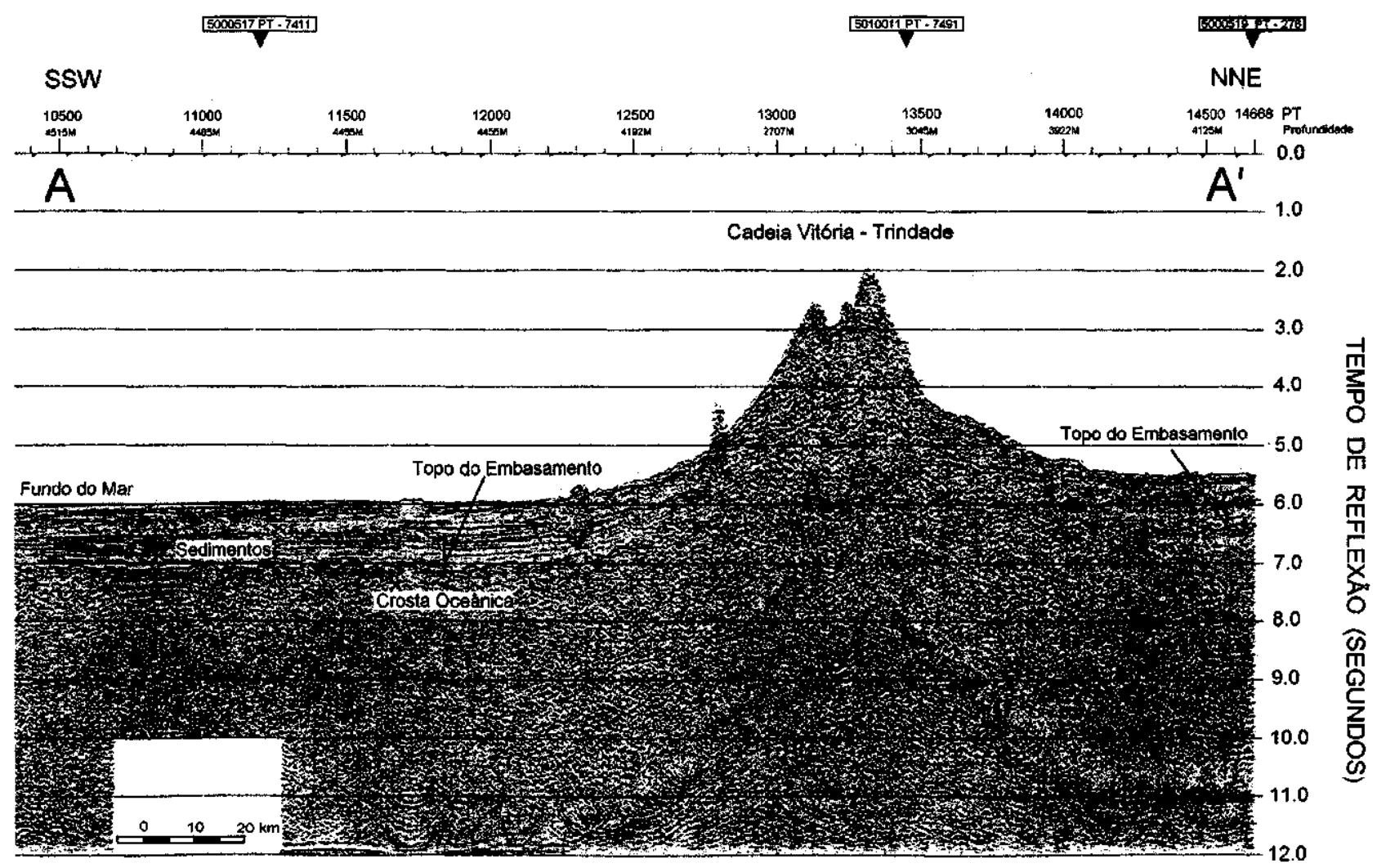

Figura 6 - Perfil sísmico regional na porção mediana da Cadeia Vitória-Trindade (Figura 1) mostrando um desnivelamento do fundo do mar e do topo do embasamento, de mais de $500 \mathrm{~m}$, entre os domínios ao norte e ao sul da cadeia. O tempo de reflexão é duplo e a velocidade intervalar média considerada é de $2000 \mathrm{~m} / \mathrm{s}$. Perfil cedido pelo Projeto LEPLAC (Marinha do Brasil/PETROBRÁS). 
atividade na chegada à margem continental. Numerosas bacias paleogênicas de pequenas dimensões, como Gandarela (Sgarbi et al. 1992), Gongo Soco (Saadi et al. 1992) e Fonseca (Sant'Anna 1994), ocorrem no Craton do São Francisco alinhadas com o traço inferido da Pluma de Trindade, e podem estar geneticamente relacionadas ao soerguimento provocado pela pluma. A tectônica deformadora da Bacia do Fonseca, de caráter extensional (Sant'Anna et al. 1997), reforça esta inferência.

A restricão do magmatismo associado à Pluma de Trindade ao Banco de Abrolhos, na .margem continental, ao norte da projeção para oeste da Cadeia Vitória-Trindade, e coincidente com a porção de litosfera afinada relacionada à Bacia do Espírito Santo, parece refletir a tendência do material das plumas de migrar para áreas com litosfera afinada (Epp 1984, Thompson \& Gibson 1991, Sleep 1997). Neste caso, a Zona de Fratura de Vitória-Trindade pode ter sido responsável por mecanismo semelhante, canalizando o magmatismo associado à Pluma de Trindade, tendo em vista $\mathrm{o}$ afinamento litosférico associado às zonas de fratura (White et al 1984). Este afinamento é verificado mesmo em zonas de fraturas com pequeno rejeito, denominadas descontinuidades de $2^{\mathrm{a}}$ e $3^{\mathrm{a}}$ ordens, e com taxas de espalhamento lento, como as do Atlântico (Fox et al. 1991).

\section{A SEGMENTAÇÃO DA CADEIA VITÓRIA-TRINDADE}

Considerando-se que a Cadeia Vitória-Trindade teria se formado a partir da migração da Placa Sul-Americana sobre o Hot Spot de Trindade e levando-se em consideração a idade média do vulcanismo de Abrolhos, de 47,5 Ma, como sendo a de chegada do centro da pluma à margem continental, e a distância do litoral à Ilha de Martin Vaz (de aproximadamente $1100 \mathrm{~km}$ ), pode-se inferir a velocidade média relativa de movimentação da Placa Sul-Americana sobre a Pluma de Trindade, entre os paralelos $20^{\circ}$ e $21^{\circ} \mathrm{S}$, como sendo de $23,1 \mathrm{~mm} / \mathrm{ano}$, compatível com outras estimativas feitas para o Atlântico Sul (Brozena 1986, Cande et al. 1988, Carbotte et al 1991). Neste sentido, a partir do valor médio de migração da placa pode-se inferir os intervalos de idade de formação para cada segmento com orientação distinta da Cadeia de Vitória-Trindade. Para isto foi escolhido o segmento da cadeia entre o limite oeste do Banco de Vitória e o limite leste da base da Ilha de Martin Vaz, com um comprimento total de $1005 \mathrm{~km}$ (Figura 1). Considerando-se a velocidade média de espalhamento, este segmento da cadeia teria se formado em 43,5 Ma. Segundo o modelo aqui adotado, esta seria a idade do vulcanismo mais antigo do Banco de Vitória, compatível com os 41 Ma determinados para o vulcanismo mais recente do Banco de Abrolhos (Cordani 1970, Cordani \& Blaze-covik 1970), situado imediatamente ao norte. Foram discriminados nesta porção da Cadeia Vitória-Trindade quatro segmentos com orientação distinta, sendo o mais antigo o que engloba o Banco de Vitória, a oeste, e o mais novo o constituído pelas ilhas da Trindade e de Martin Vaz, a leste (Tabela 1, Figura 1).

Dos quatro segmentos listados na Tabela 1, ressalta-se o mais novo, que apresenta orientação segundo a direção NW entre 3,69 Ma e o presente, compatível com a idade do vulcanismo das ilhas da Trindade e Martin Vaz.

Considerando-se que o $\mathrm{SH}_{\max }$ no interior da Placa Sul-Americana exibe uma boa concordância com a direção de movimentação da placa e com o empurrão exercido pela Cordilheira Meso-Atlântica (ridge push), mormente na sua porção oceânica (Zoback et al. 1989, Richardson 1992, Coblentz \& Richardson 1996), e que na Placa Sul-Americana o empurrão da cordilheira é responsável por cerca de $80 \%$ do esforço compressivo (Stefanick \& Jurdy 1992), foram comparadas as mudanças na posição do pólo de rotação da Placa Sul-Americana com as inflexões na orientação da cadeia (Tabela 2). Adicionalmente foram verificadas as variações na velocidade de deslocamento da Placa Sul-Americana.

Para Cande et al. (1988) a última variação de pólo no Atlântico Sul teria se dado no chron 5, há aproximadamente 8,92 Ma. Já Brozena (1986) e Carbotte et al. (1991) identificaram uma mudança de posição no pólo de espalhamento ainda mais jovem, há 4 Ma (chron 3). Segundo Brozena (1986) estas variações foram acompanhadas de mudanças nos rejeitos das falhas transformantes, na sua direção e de variações no campo de esforços. Para Carbotte et al. (1991) as variações na posição do pólo de espalhamento, apesar de terem alterado a direção das falhas transformantes, teriam provocado mudanças no rejeito somente nas descontinuidades de $2^{\mathrm{a}}$ ordem, caracterizadas por apresentarem rejeitos da crista da cordilheira menores do que as falhas transformantes $(<50 \mathrm{~km})$. Outras marcantes mudanças na posição do pólo de movimentação relativa entre as placas Sul-Americana e Africana ao longo do Terciário ocorreram no chron 27 (63,3 Ma) e no chron 13 (35,29 Ma) (Cande et al. 1988). Impor- tantes variacões na velocidade de espalhamento ao longo do Cretáceo Superior e Terciário ocorreram no chron 30 (66,74 Ma), com acentuada diminuição da velocidade de espalhamento, e no chron 20 (44,66 $\mathrm{Ma}$ ) com acentuado aumento da velocidade de espalhamento. Diminuições da velocidade de espalhamento não tão intensas quanto a do chron 30 são observadas nos chrons $13(35,29 \mathrm{Ma})$ e $6 \mathrm{c}(23,27 \mathrm{Ma})$ (Cande et al. 1988, Mello \& Dias 1996). Uma diminuição na velocidade de espalhamento entre os chrons 4A a $2(7,9$ a $1,66 \mathrm{Ma})$, identificada por Carbotte et al. (1991), é corroborada por Brozena (1986) e Cande et al. (1988), que apontam a taxa de espalhamento mais baixa no chron 3 (3,86 Ma). Um novo incremento na velocidade de espalhamento foi verificado após a anomalia Jaramillo (0,94 Ma) (Carbotte et al. 1991).

DISCUSSÃO A partir da Tabela 2 pode-se observar que há uma contemporaneidade entre as variações de orientação nos diversos segmentos da Cadeia Vitória-Trindade e as mudanças na direção de movimentação da Placa Sul-Americana e na sua velocidade. As variações de velocidade identificadas se referem tanto a um aumento como a uma diminuição. Para o segmento A, com orientação NE-SW, registra-se um aumento na velocidade de movimentação da placa e

Tabela 1 - Idade e orientação dos diversos segmentos da Cadeia Vitória - Trindade

\begin{tabular}{|c|c|c|}
\hline SEGMENTOS & IDADE & ORIENTAÇÃO \\
\hline A & $43,50-35,50 \mathrm{Ma}$ & NE \\
\hline B & $35,50-24,14 \mathrm{Ma}$ & NW \\
\hline C & $24,14-3,69 \mathrm{Ma}$ & E-W \\
\hline D & $3,69-0 \mathrm{Ma}$ & NW \\
\hline
\end{tabular}

Tabela 2 - Comparação entre as variações na direção e na velocidade de movimentação da Placa Sul-Americana desde o início da formação da Cadeia Vitória-Trindade, com o magmatismo do Banco de Abrolhos, compiladas a partir de Brozena (1986), Cande et al. (1988), Carbotte et al. (1991) e Mello \& Dias (1996), e as mudanças de orientação da Cadeia Vitória-Trindade. As idades dos diversos segmentos da Cadeia Vitória-Trindade foram calculadas a partir da velocidade média de movimentação da Placa Sul-Americana nos últimos 47,5 Ma (idade média do magmatismo do Banco de Abrolhos), considerada aqui como a idade da chegada do centro da Pluma de Trindade à margem continental.

\begin{tabular}{|c|c|c|c|}
\hline $\begin{array}{c}\text { Idade } \\
\text { Ma }\end{array}$ & Segmentos & $\begin{array}{l}\text { Mudanças de } \\
\text { Pólo }\end{array}$ & $\begin{array}{c}\text { Mudanças de } \\
\text { Velocidades }\end{array}$ \\
\hline $0-2$ & $\mathbf{D}$ & & $0,94(\mathrm{~J})$ - aumento \\
\hline $2-4$ & 3,69 & $3,86(\mathrm{C} 3)$ & 3,86 (C3) - menor velos. \\
\hline $4-6$ & \multirow{9}{*}{$\mathrm{C}$} & & \\
\hline $6-8$ & & & $7,90(\mathrm{C} 4 \mathrm{a})-$ diminuição \\
\hline $8-10$ & & $8,92(\mathrm{C} 5)$ & \\
\hline $10-12$ & & & \\
\hline $12-14$ & & & \\
\hline $14-16$ & & & \\
\hline $16-20$ & & & \\
\hline $20-22$ & & & \\
\hline $22-24$ & & & \\
\hline $24-26$ & 24,14 & & $\begin{array}{c}-25 \text { (entre C6c e C7) - } \\
\text { aumento }\end{array}$ \\
\hline $26-28$ & \multirow[t]{3}{*}{$\mathbf{B}$} & $26,86(\mathrm{C} 8)$ & \\
\hline $28-30$ & & & \\
\hline $32-34$ & & & \\
\hline $34-36$ & 35,50 & $35,29(\mathrm{C} 13)$ & $\begin{array}{c}35,29(\mathrm{C} 13)-\text { diminuição } \\
\text { brusca }\end{array}$ \\
\hline $36-38$ & \multirow{2}{*}{$\mathbf{A}$} & & \\
\hline $38-40$ & & & \\
\hline $42-44$ & 43,50 & & \\
\hline $44-46$ & & $44,66(\mathrm{C} 20)$ & $\begin{array}{l}44,66(\mathrm{C} 20) \text { - aumento } \\
\text { brusco }\end{array}$ \\
\hline \multicolumn{4}{|l|}{$46-48$} \\
\hline \multicolumn{4}{|l|}{$48-50$} \\
\hline $52-54$ & & & \\
\hline
\end{tabular}


para os segmentos B e D, com orientação NW-SE, registra-se uma diminuição na velocidade de movimentação da placa. Esta relação, porém, não se repete no segmento $\mathrm{C}$, onde um aumento na velocidade de movimentação da placa corresponde a uma orientação E-W da cadeia. As variações na posicão do pólo de movimentacão da Placa Sul-Americana foram no sentido horário entre os chrons 34 (84 Ma) e 21 (48,75 Ma), e no sentido anti-horário desde então (Cande et al. 1988). Considerando-se que a Ilha da Trindade está posicionada em crosta formada entre os chrons 34 e 33, e que no chron 13 (35,29 Ma) a linha de fluxo da Placa Sul-Americana voltou a coincidir com aquela do chron 34 (Cande et al. 1988), toda mudança na direção de movimentação da placa após o chron 13 foi também anti-horária com relação a um eventual segmento de zona de fratura que tenha controlado a formação da Ilha da Trindade. Desta forma, considerando-se um comportamento rígido da placa, ter-se-ía a atuação de um $\mathrm{SH}_{\max }$ de direção ENE-WSW a NE-SW, o qual, em se tratando de $\sigma 1$ produziria uma movimentação transpressiva (McCarthy et al. 1996) e sinistrai, numa eventual reativação daquele segmento da zona de fratura. Esse arranjo dos tensores seria oposto ao estabelecido para o controle da intrusão dos diques da Ilha da Trindade no Plio-Pleistoceno. Desta forma, o campo de esforços inferido para a Ilha da Trindade no Plio-Pleistoceno só seria possível com um comportamento não rígido da Placa Sul-Americana e com a deformação a ele associada propagando-se no seu interior.

Um comportamento não rígido da placa Sul-Americana foi inferido a partir de heterogeneidades na velocidade de espalhamento em diferentes segmentos da Cadeia Meso-Atlântica, no intervalo de tempo de uma anomalia magnética, relacionadas a respostas diferenciadas de cada segmento da cadeia às variações no movimento das placas SulAmericana e Africana (Carbotte et al. 1991). Estas heterogeneidades seriam absorvidas nos seus limites por alongamento e encurtamento nos rejeitos das zonas de fraturas e por extensão não mag-mática (Fox et al. 1991). Por outro lado, diversos autores têm especulado sobre a relação entre variações na direção de movimentação e na velocidade de espalhamento das placas e ativações tectono-magmáti-cas intraplaca (Marsh 1973, Asmus 1978, Sykes 1978, Lowrie et al. 1986, Sadowsk 1987. Conceição et al. 1988, Riccomini 1989,1995, Pereira 1992, Sandwell et al. 1995, Binnard et al. 1996, Mello \& Dias 1996).

A resistência a esforcos cisalhantes em zonas de fraturas é, em média, de $20 \mathrm{MPa}$, variando entre 5 e $40 \mathrm{MPa}$ e diminuindo quando posicionadas sobre hot-spots (Jordahl et al. 1996, Kruse et al. 1996). Os valores de $\mathrm{SH}_{\max }$ inferidos para a porção oceânica da Placa SulAmericana, entre 20 MPa (Coblentz \& Richardson 1996) e $15 \mathrm{MPa}$ (Assumpcão 1998), conjugados com esforços locais associados ao relevo anómalo de quase $600 \mathrm{~m}$ acima do nível do mar na Ilha da Trindade, ao espessamento crustal, e aos efeitos da Pluma de Trindade sobre a reologia e espessura elástica da placa, permitem especular sobre a superação da resistência ao rompimento da Zona de Fratura de Trindade, segundo um regime strike-slip, à semelhança da maior parte da porção emersa do território brasileiro (Coblentz \& Richardson 1996). Neste sentido, reativações de caráter transpressivo e transtrativo foram reconhecidas por Silveira et al. (1994), na Zona de Fratura de São Paulo, na margem equatorial brasileira. A inexistência de sismos ao longo da Cadeia de Vitória-Trindade (Marcelo Assumpção 1998, informacão verbal) não reforça esta hipótese. Um único sismo foi registrado na região nos últimos 43 anos, imediatamente ao norte do Banco de Vitória (Mendiguren \& Richter 1955). Este sismo teve intensidade $6,2\left(\mathrm{~m}_{\mathrm{b}}\right)$, mecanismo focal inverso e $\mathrm{SH}_{\mathrm{max}}$ de direção ENE. Deve-se ressaltar que a inferência da direção de $\mathrm{SH}_{\max }$ tem ampla margem de erro (Marcelo Assumpção 1998, informação verbal). A origem deste sismo foi relacionada por Assumpcão (1993) ao somatório dos esforços associados ao ridge push e ao flexuramento da litosfera na margem continental, em especial junto ao talude, tendo em vista ocorrerem aí as maiores espessuras de sedimentos. De fato, uma acumulação sedimentar anómala no sopé continental, de $5 \mathrm{~km}$ de espessura, que constitui a denominada Bacia dos Abrolhos (Francisconi \& Kowsmann 1976), tem depocentro sobre o limite entre as crostas continental e oceânica indicado por Chang et al. (1992) e imediatamente ao norte do referido epicentro. Porem o epicentro se posiciona mais próximo da Cadeia Vitória-Trindade $(\sim 30 \mathrm{~km})$ do que do depocentro da Bacia dos Abrolhos $(\sim 80 \mathrm{~km})$.

Por outro lado, deve-se notar que os mecanismos de esforços inferidos a partir de alguns dos segmentos da Cadeia Vitória-Trindade, segundo o modelo aqui proposto, são compatíveis com aqueles identificados na área emersa adjacente. Por exemplo, a orientação ENE do Banco de Vitória, com idade de formação aqui inferida entre 43,5 e
35,5 Ma, requer um $\mathrm{SH}_{\max }$ nesta mesma direção, compatível com o caracterizado para o controle tectônico do magmatismo alcalino no Estado do Rio de Janeiro, entre o Cretáceo Superior e o Eoceno, sendo que neste caso o $\mathrm{SH}_{\max }$ corresponde a ol (Riccomini et al. 1983, Riccomini \& Rodrigues Francisco 1992, Ferrari et al 1997a, b). Também a inferência de um SHmax de direção NW para o Plio-Pleistoceno, a partir da Ilha da Trindade, encontra respaldo na área continental emersa adjacente, tanto no Rift Continental do Sudeste do Brasil (Riccomini 1989,1995, Riccomini et al 1989, Salvador \& Riccomini 1995, Ferrari et al. 1997a, b), onde Riccomini $(1989,1995)$ relacionou as variações no campo de esforcos ao longo do Terciário ao balanço entre as taxas de espalhamento e subducção nos limites da placa, como na área emersa adjacente à Bacia de Campos (Silva \& Ferrari 1997) e, ainda, no Vale do Rio Doce (Mello 1997), na projeção para oeste da Cadeia Vitória-Trindade, correspondendo, também neste caso, a $\sigma 1$. Entretanto, no caso das deformaçoes do Eoceno Médio e Oligoceno extensão NNW-SSE - e do Mioceno - transcorrência sinistrai E-W -(Riccomini 1989, 1995), esta relação não é clara. Também para a extensão E-W a NW-SË, do final do Pleistoceno, e para a compressão EW holocênica (Riccomini et al. 1989, Salvador \& Riccomini 1995, Mello 1997) esta correlação não é evidente. Neste último caso, no entanto, deve-se registrar que apesar de não ter ocorrido nenhuma mudança na direção de movimentação da Placa Sul-Americana no final do Pleistoceno, verificou-se uma aceleração na sua velocidade de migração a partir da anomalia Jaramillo (Carbotte et al 1991), no Pleistoceno Médio (0,97 Ma). Assim, pode-se supor que a aceleração na velocidade de movimentação da Placa Sul-Americana tenha causado uma mudança no campo de esforços na área emersa do sudeste brasileiro, junto à costa, de uma extensão E-W a NW-SE para uma compressão E-W.

Desta forma, conclui-se que as variações de orientação verificadas nos diversos segmentos da Cadeia Vitória-Trindade refletem principalmente variações na velocidade de espalhamento e, secundariamente, variações na posição do pólo de rotação da Placa Sul-Americana.

CONCLUSÕES Os diques do setor nordeste da Ilha da Trindade, de direção NW e mergulho subvertical, são compatíveis com um regime de cisalhamento simples, com o eixo de tensões principal máximo, $\sigma_{l}$, na direção dos diques, associado a um binário dextral de direção aproximada segundo ENE-WSW a E-W.

A concordância entre a orientação dos diques com a forma da Ilha da Trindade e de seu edifício vulcânico sugerem um controle tectônico único durante sua formação. As orientações distintas desta, identificadas em outros segmentos da Cadeia Vitória-Trindade, provavelmente refletem mudanças na direção de $\sigma 1$ ao longo do Terciário. $\mathrm{O}$ arranjo en echelon de alguns destes segmentos indica que o regime de cisalhamento simples foi efetivo em boa parte de sua evolução. A compatibilidade parcial das variações na direção de $\sigma 1$ entre a área oceânica e a continental no sudeste do Brasil evidenciam a importância dos esforços locais, nessas áreas, e sua variabilidade ao longo do Terciário.

As diferenças na profundidade do embasamento ao norte e ao sul da Cadeia Vitória-Trindade corroboram a existência de uma zona de fratura, que deve ter atuado como conduto para o magmatismo da Pluma de Trindade.

A incompatibilidade entre a direção de $\mathrm{SH}_{\max }$ esperada para o Plioceno e Pleitoceno na Ilha de Trindade e a direção dos diques do segmento nordeste da ilha implica num comportamento não rígido deste segmento da placa Sul-Americana.

Agradecimentos Os autores agradecem aos Drs. Eliane da Costa Alves, Jorge Jesus da Cunha Palma, Marcos Aguiar Gorini e Sidney de Matos Mello (LAGEMAR/UFF), Dr. Victor Velázquez Fernandez (IG/USP) e Dra. Mareia Maia (BREST) pelas sugestões e incentivo; ao Dr. Joe R.Cann (LEEDS) pelas exaustivas discussões e sugestões que muito contribuíram para a melhoria do texto; aos consultores da Revista Brasileira de Geociências pela revisão crítica do manuscrito; ao Programa de Apoio ao Desenvolvimento Científico e Tecnológico

- PADCT (processo 65930433-00) e à Fundação de Amparo à Pesquisa do Estado de São Paulo -FAPESP (processo 97/12091-6) pelo financiamento dê parte da pesquisa; ao Plano de Levantamento da Plataforma Continental Brasileira (Projeto LEPLAC), da Marinha Brasileira e PETROBRÁS, pela liberação da linha sísmica utilizada e, à Sra. Thelma Samara e ao Sr. Marcos Antônio dos Santos pela confecção de parte das figuras. 
Aguiar, A.C.K.V. 1997. Estudo grovimétrico da morfologia e cia estrutura crustal 3D da porção ocidental do Atlântico Sul entre os paralelos lffS e 4(fS. Observatório Nacional - CNPq, Rio de janeiro, Dissertação de Mestrado, 124 p.

Almeida, F. F. M. 1961. Geologia e Petrologia da Ilha da Trindade. DGM/DNPM, monografia XVIII, $197 \mathrm{p}$

Almeida, F. F. M. 1965. As ilhas oceânicas brasileiras e uma hipótese sobre a origem do Attântico. Anais da Academia Brasileira de Ciências, Rio de Janeiro, 37 (supl.):141-145

Anderson, E. M. 1951. The dynamics offaulting and dyke formation with applications to Britain. Edinburg, Oliver \& Boyd, $206 \mathrm{p}$.

Asmus, H.E. 1978. Hipóteses sobre a origem dos sistemas de zonas de fratura oceânicas/alinhamentos continentais que ocorrem nas regiões sudeste e sul do Brasil, Rio de Janeiro, CENPES/DINTEP, p. 39-73 (Série Projeto REMAC 4) Asmus,

H.E.; Gomes, J.B. \& Pereira, A C.B. 1971. Integração geoló gica regional da Bacia do Espírito Santo: In: SBG, Congresso Brasileiro de Geologia, 25, São Paulo, Anais, 3:325-252 Assumpção, M. 1993. Earthquakes and stresses in the Brazilian

Continental Margin. In: SBGf, Congresso Internacional da Sociedade Brasileira de Geofísica, 3, Rio de Janeiro, Anais, p. 1128-1133

Assumpcão, M. 1998. Seismicity and Stresses in the Brazilian Passíve Margin. Bulettin of the Seismological. Society of America, 88(1):160-169..

Basset, K.N. \& Kleinspein, K.L. 1996. Mid-Cretaceous transtension in the Canadian Cordillera: Evidense from the Rock Ridge volcanics of Skeena Group. Tectonics, 15(4):727-746

Binard, N.; Stoffers.P.; Hékinian.R. \& Seark, R.C. 1996. Intraplate en echelon volcanic ridges in the South Pacific west of the Easler Microplate. Tectonophysics, 263:23-37

Brozena, J. M. 1986. Temporal and spatial variability of sea floor spreading processes in the northern South Atlantic. Journal of Geophysical Research, 91:497-510

Cande, S. C.; Labrecque, J.L.; Haxby, W.F. 1988. Plate kinematies of the South Atlantic: chron 34 to present. Journal of Geophysical Research., 93:13497-13492

Carbotte, S.; Welch, R.N.; Mcdonald, K.C. í991. Spreading rates, rift propagation, and fracture zone offset histories during the past $5 \mathrm{my}$ on the mid-atlantic ridge; $25-27 \quad 30^{\prime} \mathrm{S}$ and $31-3430^{\prime} \mathrm{S}$. Marine Geophysical Research, 13:51-80

Carvalho, J.C. \& Francisconi, O. 1981. Análise de depocentros e suas associações com a geomorfologia e a estrutura da Margem Continental Brasileira. In: Asmus, H.E., Ed. Estruturas e tectonismo da Margem Continental Brasileira e suas implicações nos processos sedimentares e na avaliacão do potencial de recursos minerais. Rio de Janeiro, CENPES/DINTEP, p. 171-186, (Série Projeto REMAC 9)

Chang, H.K.; Kowsman, R.; Figueiredo, A.M.F. \& Bender, A.A. 1992. Tectonics and stratigraphy of the east Brazil rift system: an overview. Tectonophysics, 213:97-138

Coblentz, D.D. \& Richardson, R.M. 1996. Analysis of the South American intraplate stress field, Journal of Geophysical Research., 101(B4):8643-8657

Conceição, J.C.J.; Zalán, P. V. \& Wolf, S. 1988. Mecanismo, evolução e cronologia do rift Sul-Atlântico. Boletim de Geociências da Petrobrás 2(2/4):255-265

Conceição, J.C.J., Misuzaki, A.M.P., Alves, D.B. \& Szatmari, P. 1996. Controle tectônico do maomatismo do Complexo Vulcânico de Abrolhos, Bacia do Espírito Santo. In: SBG, Congresso Brasileiro de Geologia, 39, Camboriu, Anais, 5:384-387

Cordani, U.G. 1970. Idade do vulcanismo no oceano Atlântico. Boletim de Geociências e Astronomia, 1:9-75

Cordani, U.G. \& Blazekovic, A. 1970. Idades radiométricas das rochas vulcânicas de Abrolhos. In: SBG, Congresso Brasileiro Geologia, Porto Alegre, Anais, 265-270

Crough, S. T.; Morgan, W. J.; Hargaves, R.B. 1980. Kimberlites: their relation to mantle hot spots. Earth and Planetary Science Letters, 50:260-274

Dalrymple, G. B. 1974. Criticai tables for conversion of K-Ar ages from old to new constants. Geology, 7: 558-560.

Epp, D. 1984. Possible perturbations to hotspot traces and the implications for the origin and structure of the Line Islands. Journal of Geophysical Research., 89(B13) : $11273-11286$

Fernandez, C.; Casulas, R.; Ahijado, A; Perello, V.E \& Pacheco, A.H. 1997. Shear zones as a result of intraplate tectonics in the oceanic crust: the exemple of the basal complex of Fuerteventura (Canary Islands). Journal of Structural Geology, 19(1): $41-57$

Ferrari, A.L.; Silva, M.A.M. \& Penha, H.M. 1997a. Persistência de Shmax com direção NE no segmento nordeste do Rift Continental do Sudeste do Brasil ao longo do Cretáceo Superior e Terciário. Anais da Academia Brasileira de Ciências, resumos das sessões, 69 (3): 440

Ferrari, A.L.; Silva, M.A.M. \& Penha, H.M. 1997b. Variações no campo de esforços na área emersa adjacente ao Alto de Cabo Frio ao longo do Cretáceo e Terciário. In: SBG/Núcleo Rio de Janeiro, Simpósio de Geologia do Sudeste, 5, Resumos Expandidos, Itatiaia - RJ, 89-91

Fleitout, L.; Dallowbeix, C. \& Moriceou, C. 1989. Small-wave lenght geoid and topography anomalies in the South Atlantic ocean: a clue to new hot-spot tracks and lithospheric deformation. Geophysical Research Letters, 16(7):637-640

Fox, P.J.; Grindlay, N.R.; Macdonald, K.C.; Carbotte, S.M.; Forsth, D.W. \& Kuo, B.Y. 1991. The Mid-Atlantic Ridge $\left(31^{\circ}-34^{\circ} 30^{\prime}\right)$ : Temporal and Spatial Variations of Accrescionary Processes, Marine Geophysical Research, 13:1- 20.

Francheteau, J. \& Lê Pichon, X. 1972. Marginal fracture zones as structural framework of continental margins in South Atlantic Ocean. American Association of Petroleum Geologists Bulletim, 56(6): 991 - 1007

Francisconi, O. \& Kowsmann, R.O. 1976. Preliminary structural study of the South Brasilian Continental Margin. Anais da Academia Brasileira de Ciências, Simpósio Internacional sobre Margens Continentais do Tipo Atlântico, Rio de Janeiro, 48(Supl.): $89-100$

Geoffroy, L.; Bergerat, F. \& Angelier, J. 1993. Modification d'un champ de contrainte regional par un champ de contraintes magmatique local. Exemple de I'île de Skye
(Ecosse) au Paléocène. Bulletin de Societé Géologique de France, 164 (4): 541-552

Gibson, S. A., Thompson, R. N.; Leonardos, O.H.; Dickin, A. P. 1995. The late Cretaceous impact of the Trindade mantle plume: evidence from large volume, mafic, potassic magmatism in SE Brasil. Journal of Petrology, 36(I): 189-229

Gomes, P.O. 1997. O Projeto Leplac na margem continental nordeste: Imagens sísmicas de flexura litosférica junto a zonas de fratura. In: SBGf, Congresso Internacional da Sociedade Brasileira de Geofísica, 5, Rio de Janeiro, Anais,]: 18-21
Gorini, M.A. \& Carvalho, J.C. 1984. Geologia da margem continental inferior brasileira e do fundo oceânico adjacente. In: Schobbenhaus, C; Campos, D. A.; Derze, G.R.; Asmus, H.E., Geologia do Brasil, coord.: Texto explicativo do Mapa Geológico do Brasil e da área oceânica adjacente incluindo depósitos minerais - Escala 1.2500000. MME/DNPM, Brasília, p. 473-489

Guazelli, W. \& Carvalho, J.C. 1978. A extensão da Zona de Fratura de Vitória-Trindade no oceano e seu possivel prolongamento no continente, Rio de Janeiro, CENPES/DINTEP, p. 31-38, (Série Projeto Remac 4)

Guazelli, W. \& Carvalho, J.C. 1981. Estruturas da margem continental leste Brasileira e das áreas oceânicas e continentais adjacentes. In: Asmus, H.E., Ed. Estruturas e tectonismo da Margem Continental Brasileira e suas implicaçõ es nos processos sedimentares e na avaliacão do potencial de recursos minerais, Rio de Janeiro, CENPES/DINTEP, P. 117-143 (Série Projeto REMAC 9)

Hartnady, W. J. \& Lê Roex, A.P. 1985. Southern ocean hot spot tracks and Cenozoic absolute motion of the African, Antartic and South American plates. Earth and Planetary Science Letters, 75:245-257

Herz, N. 1977. Tirning of spreading in the South Atlantic: information frombrazilian alcalic rocks. Geological Society of America Bulletin, 88:101-112

Hill, R. I. 1991. Starting plumes and continental break -up. Earth and Planetary Science Letters, 104:398-416

Jordhal, K. A.; McNutt, M.K.; Webb, H.F.; Kruse, S.E. \& Kuykendal, M.G. 1995. Why there are no earthquakes on the Marquesas Fracture Zone? Journal of Geophysical Research, 100(B12):24431-24447

Kruse, S.E.; McCarthy, M.C.; Brudzinski, M.R. \& Ranieri, M.E. 1996. Evolution and strenght of Pacific fracture zones. Journal of Geophysical Research, 101(B6):13731-13740

Lowrie, A.; Smoot, C. \& Batiza, R. 1986. Are oceanic fracture zones locked and strong or weak?: New evidence for volcanic activity and weakness. Geology, 14:242-245

Marinoni, L. \& Pasquaré, G. 1994. Tectonic evolution of the emrgent part of volcanic ocean island: Lanzarote, Canary Islands. Tectonophysics, 239:111-135

Marsh, J. S. 1973. Relationships between transform directions and alcaline igneous rock lineaments in Á frica and South America. Earth and Planetary Science Letters, 18:317-323

McAllister, E. \& Cann, J. 1995. The evolution of crustal deformation in na oceanic extensional enviroment. Journal ofStructural Geology, 17(2): 183-199

McCarthy, M.C.; Kruse, S.E.; Brudzinski, M.R. \& Manieri, M.E. 1996. Changes in the pacific plate motions and the shape of pacific fracture zones. Journal of Geophysical Research, 101(B6):13715-13370

McNutt, M.; Fisher, K.; Kruse, S.; \& Natland, J. 1989. The origin of the Marquesas fracture zone ridge and its implications for the nature of hot spots. Earth and Planetary Science Letters, 91:381-393

Mello, C.L. 1997. Sedimentação e tectônica cenozóicas no Médio Vale do Rio Doce (MG, Sudeste do Brasil) e suas implicações na evolução de um sistema de lagos. Instituto de Geociências da Universidade de São Paulo, Tese de Doutorado, 275 p.

Mello, S.L.M. \& Dias, M.S. 1996. Magnetoestratigrafia da crosta oceânica entre as zonas de fratura de Ascensão e Bode Verde. Revista Brasileira de Geofisica, $14(3): 237-251$

Mendiguren, J. A. \& Richter, F.M. 1978. On the origin of compressional intraplate stresses in South America. Physics of Earth and Plantary Interiors, 16:318-316

Mohriak, W. U., Barros, A. Z. N. \& Fujita, A. 1990. Magmatismo e tectonismo cenozóico na região de Cabo Frio, RJ. In: SBG, Congresso Brasileiro de Geologia, 37, Natal, Anais, 6:2873-2884

Morgan, W. J. 1968. Rises, trenches, great faults, and crustal blocks. Journal of Geophysical Research, 73:1959-1982

Morgan, W. J. 1983. Hot spot traks and the early rifting of the of the atlantic. Tectonophysics, 94:123-139

O'Connor, J. M. \& Duncan, R. A. 1990. Evolution of the Walvis ridge - Rio Grande rise hot spot system: Implications for African and South American plate motions over plumes. Journal of Geophysical Research, 95:17475-17502

Pereira, J.P. 1992. Consideraçõ es sobre a estratigrafia do Cenomaniano-Santoniano em algumas bacias marginais brasileiras e sua implicação na histó ria tectônica e sedimentar da margem continental. Boletim de Geociências da Petrobrás, 6(3/4): $171-176$

Richardson, R. M. 1992. Ridge forces, absolute plate motions, and the intraplate stress field. Journal of Geophysical Research, 97(B7): 11905-11913

Riccomini, C. 1989. O Rift Continental do Sudeste do Brasil. São Paulo, 256p. Instituto de Geociências da Universidade de São Paulo, São Paulo, Tese de Doutoramento, 256 P.

Riccomini, C. 1995. Tectonismo gerador e deformador dos depósitos sedimentares Pós-Gondwânicos da porção centro-oriental do Estado de São Paulo e áreas vizinhas. Instituto de Geociências da Universidade de São Paulo, São Paulo, Tese de Livre Docência, $100 \mathrm{p}$

Riccomini, C. \& Rodrigues Francisco, B. H. 1992. Idade potássio-argônio do derrame de ankaramito da Bacia de Itaboraí, Rio de Janeiro, Brasil: implicações tectônicas. In: SBG, Congresso Brasileiro de Geologia, 37, São Paulo, Resumos Expandidos, 1:469-470

Riccomini, C.; Melo, M. S.; Carneiro, C.D.R.; Almeida, F. F. M.; Mioto, J. A. \& Hasui, Y. 1983. Sobre a ocorrência de um derrame de ankaramito na bacia de Volta Redonda (RJ) e sua importância na datação das bacias trafogênicas continentais do sudeste brasileiro. In: SBG/Núcleo São Paulo, Simpósio Regional de Geologia, 4, São Pedro, Resumos. 23-24 Riccomini, C; Peloggia, A.U.G., Saloni, J.C.L., Kohnke,

M.W. \& Figueira, R.M. 1989. Neotectonic activity in the Serra do Mar rift system (Southeastern Brazil). Journal of South American Earth Sciences, 2 (2):191-197

Saadi, A; Sgarbi, G.N.C. \& Rosiére, C.A. 1992. A Bacia de Gongo Soco, nova bacia terciária no Quadrilátero Ferrífero: controle cárstico e/ou tectônico. In: SBG Congresso Brasileiro de Geologia, 37, São Paulo, Resumos Expandidos, 1:600-601

Sadowski, G. R. 1987. A possible relation between pulses of platform activation and plate kinematies. Tectonophysics, 143:43-57

Salvador, E. D. \& Riccomini, C. 1995. Neotectônica do Alto Estrutural de Queluz (SP-RJ, Brasil). Revista Brasileira de Geociências, 25(3): 151-164 
Sandwell, D.T.; Winterer, E.L.; Mammericks, J.; Duncan, R.A; Lynch, M.A; Lewitt, D A. \& Johnson, C.L. 1995. Evidence for diffuse extension of the Pacific Plate from Pukapuka Ridges and cross grain gravity lineations. Journal of Geophysical Research, 100(B8):15087-15099

Sant'Anna, L.G. 1994. Mineralogia das argilas e evolução geológica da Bacia do Fonseca, Minas Gerais. Instituto de Geociências da Universidade de São Paulo, São Paulo, Dissertação de Mestrado, $151 \mathrm{p}$.

Sant'Anna, L.G.; Schorscher, H.D. \& Riccomini, C. 1997. Cenozoic tectonics of the Fonseca Basin region, eastera Quadrilátero Ferrífero, MG, Brazil. Journal of South American Earth Sciences, 10(3-4):275-284

Sgarbi, G.N.C.; Fantinel, L. \& Masotti, F.S. 1992. Geologia dos sedimentos lacustres da bacia terciária de Gandarela, MG. Revista da Escola de Minas, 45(1/2):! 18-120

Silva, C.G. \& Ferrari, A. L. 1997. Neotectônica no litoral nordeste do Estado do Rio de Janeiro. In: SBG/Núcleo Rio de Janeiro, Simpósio de Geologia do Sudeste, 5, Resumos Expandidos, Itatiaia - RJ, 80-82

Silveira, D.P.; Gomes, S.B.; Suarez, C.R. \& Gomes, P.O. 1994. Projeto LEPLAC Interpretação integrada dos daos geofisicos do "Leplac Equatorial". In: SBG Congresso Brasileiro de Geologia, 38, Camboriu, Resumos Expandidos, 2:35-37

Sleep, N.H. 1997. Lateral flow and ponding of starting plume material. J Geophys. Res., 102(B5): 10001-10012.

Stefanic, M. \& Jurdy, D. M. 1992. Stress observations and driving force models for the south american plate. Journal of Geophysical Research., 97 (B8):1 1905-11913

Sykes, L.R. 1978. Itraplate seismicity, reactivation of pré-existing zones of weakness, alkaline magmatism and other tectonism postdating continental fragmentation: Rewies ofGeophysics and Space Physics, 16:621-688

Tchalenko, J. S. 1970. Similarities between shear zones ofdifferentmagnitudes. Geological Society of America Bulletin, 81:1625-1640

Thompson, R.N. \& Gibson, S.A. 1991. Subcontinental mantle plumes, hotspots, and pre-existing thinspots. Journal of the Geological Society ofLondon, 148:973-977
Valencio, D.A. \& Mendía, J.E. 1974. Paleomagnetism and K-Ar ages of some igneous rocks of the trindade complex and the Valado Formation, from Trindade Island, Brazil. Revista Brasileira de Geociências, 4:124-132.

VanDecar, J.C.; James, D.E. \& Assumpção, M. 1995. Seismic evidence for afossil mantle plume beneath South America and implications for plating driving forces. Nature, 378:25-31

White, R.S.; Detrick, R.S.; Sinhs, M.C. \& Carmier, M.H. 1984. Anomalous seismic crusta! structure of oceanic fracture zones. Geophysical Journal ofthe RoyalAstrronomical Society, 79:779-798

Wiens, D. A.; Stein, S.; Demeters, C.; Gordon, R.G. \& Stein, C. 1986. Plate tectonics models for Indian Ocean intraplate deformatíns. Tectonophysics, 132:37-48

Wilcox, R.E.; Harding, T.P. \& Seely, D.R. 1973. Basic wrench tectonics. American Association of Petroleum Geologists Bulletin, 57:74-96

Wilson, J.T. 1965. A new class of faults and their bearing on continental drift. Nature, 207:343-347.

Szatmari, P \& Mohriak, W. U. 1995. Plate model of post-breakup tectono-magmatic activity in the adjacent Atlantic. In: SBG/Núcleo Rio grande do Sul, Simpósio Nacional de Estudos Tectônicos, 5, Gramado, Anais, 1:213-214

Zoback et al. 1989. Global patterns of tectonic stress. Nature, 341:291-298

Zoback, M. L. 1992. First- and Second-Order Patterns of Stress in the Lithosphere: The World Stress Map Project, Journal of Geophysical Research, 97(B8): 11703-11728

Zoback, M.L. \& Richardson, R.M. 1996. Stress perturbations associated with the amazonas and other ancient continental rifts. Journal of Geophysical Research, 101:5459-5475

Manuscrito A-1020

Recebido em 12 de agosto de 1998

Revisão dos autores em 20 de janeiro de 1999 Revisão aceita em 25 de janeiro de 1999 